\title{
The upper temperature for life - where do we draw the line?
}

\author{
D.A. Cowan
}

Institute for Microbial Biotechnology and Metagenomics

A new archaeal isolate has been reported that is capable of growing at up to $121^{\circ} \mathrm{C}$. This hyperthermophile, dubbed strain 121, grows chemoautotrophically using formate as an electron donor and $\mathrm{Fe}^{\mathrm{III}}$ as an electron acceptor and is closely related to members of the archaeal genera Pyrodictium and Pyrobaculum. Although the reported maximum growth temperature of strain 121 is $8^{\circ} \mathrm{C}$ higher than the previous record holder (Pyrolobus fumarii; $T_{\max }=113{ }^{\circ} \mathrm{C}$ ), the two organisms have virtually the same optimal growth temperatures.

A publication by Kashefi and Lovley [1] has once more brought the issue of the upper temperature limit for life to the attention of the scientific community. The isolation of a hyperthermophilic archaeal strain that grows optimally at $105-107^{\circ} \mathrm{C}$, and maximally at $121^{\circ} \mathrm{C}$ is reported. At first inspection, this organism would appear to have moved the bar up by some $8{ }^{\circ} \mathrm{C}$, the previous record having been held by Pyrolobus fumarii [2]. However, some caution must be advised in interpreting these results. Strain 121 is reported to have a doubling time of $\sim 7$ hours at $115{ }^{\circ} \mathrm{C}$ and 24 hours at $121{ }^{\circ} \mathrm{C}$. By contrast, P. fumarii showed no growth at $115^{\circ} \mathrm{C}$ [2], but had a doubling time of $\sim 8$ hours at $112{ }^{\circ} \mathrm{C}$ with a significant number of cells in an exponentially growing culture surviving autoclaving. Therefore, strain 121 shows detectable growth at $8{ }^{\circ} \mathrm{C}$ above that reported for $P$. fumarii. Readers should note that measuring accurate growth rates at extremes of temperature is difficult at the best of times, and cannot be made easier by the generation of the amorphous, opaque magnetite that is the product of $\mathrm{Fe}^{11}$ reduction. However, it is remarkable that strain 121 survives at $130{ }^{\circ} \mathrm{C}$ for short periods. To put this in perspective, if $10^{7}$ cells were exposed to $130{ }^{\circ} \mathrm{C}$ and completely killed in 2 hours, we would calculate a survival half-life of $\sim 6$ minutes. The remarkable fact is that a vegetative cell can survive this long at such temperatures.

This work therefore represents another contribution to the exciting search for the upper temperature limit for life: a search that has shown a generally linear rise (see Figure 1, after References ) over the past 30 years.

Although the authors note that growth at $121{ }^{\circ} \mathrm{C}$ is remarkable because this is the temperature of sterilization, there is nothing remarkable about this temperature per se other than the fact that this is the boiling temperature of water at 1 atmosphere $(15 \mathrm{psi})$ overpressure. Had the original designers of autoclaves chosen a different overpressure (such as 20 psi), a different 'sterilization' temperature would have been embedded in our minds.

It is an exciting thought that the cardinal growth temperatures determined in laboratory studies might be underestimates of true in vivo growth temperatures. For example, the well-known extremely thermophilic aerobe Thermus Aquaticus [3] is readily isolated from terrestrial $90-100{ }^{\circ} \mathrm{C}$ hydrothermal systems, but will not grow reliably in the laboratory above $80{ }^{\circ} \mathrm{C}$ (H.W. Morgan, pers. commun.). Nevertheless, terrestrial and shallow marine environments are probably too cool to harbor the most hyperthermophilic organisms, because their 
slow growth rates at such relatively low temperatures probably result in their being out-competed by rapidly growing organisms, such as Pyrococcus [4].

The deep-sea hydrothermal vent biotopes, from which numerous hyperthermophilic archaea have been isolated, provide ample scope for high temperature growth. The friable metal sulfide walls of'smoker' chimneys offer huge, if rather steep temperature gradients. The temperature of the interior water column might be as high as $400{ }^{\circ} \mathrm{C}$, whereas the external seawater temperature is typically less than $5{ }^{\circ} \mathrm{C}$, generating a temperature gradient of several hundred degrees over a few tens of centimeters in the chimney walls [5]. Horizontal transect samples from smoker chimneys have shown that biological signals, in the form of amplifiable 16S rRNA genes, are present across much of the transect [5,6]. Unfortunately, the fragility of the chimneys and the difficulties of maneuvering instruments using the remote arms ofsubmersibles mean that it has not been possible to correlate the biological signatures with the thermal gradient. To do so would provide an elegant means of providing a culture-independent measure of the upper temperature limit for life.

\section{The molecular basis of thermophily}

The enthusiastic analysis of molecular stability [7-10], which has closely followed the growth of the field of 'thermophily', appears to have waned in the past five years, leaving many fundamental questions unanswered. It would therefore be beneficial for thermophile research in general if the Kashefi and Lovley publication [1] triggered another debate on the molecular mechanisms that dictate the ability (or inability) of an organism to grow at high temperatures. Protein structural analysis [7,10] has indicated that conformational stability might not be the limiting factor; proteins possessing high levels of thermostability ( $\mathrm{T}_{\mathrm{m}}$ values in excess of $130{ }^{\circ} \mathrm{C}[11]$ ) have been characterized. Strain 121 will probably yield more examples of thermostable proteins, the study of which should further contribute to our understanding of the molecular basis of protein stability. For example, a high-resolution crystal structure of the glutamate dehydrogen-ase will probably be a very useful addition to the protein series that exposed the vital contribution of salt-bridge networks to protein conformational stability [12,13]. Although we believe that we have at least some understanding of protein structural stability, our understanding of the implications of chemical instability at high temperatures is less developed. Studies from the early 1980s indicated that natural amino acids are reasonably chemically stable up to around $150{ }^{\circ} \mathrm{C}$, but are degraded in minutes or even seconds at $250{ }^{\circ} \mathrm{C}[10,14]$. Therefore, the conformational stabilty of proteins and the inherent chemical stability of their constituent amino acids suggests that hyperthermophiles should not face a particularly high maintenance energy burden owing to an increased protein for protein structural repair or resynthesis [10]. The same might not apply to other cell constituents, such as coenzymes [e.g. NAD/P(H)] and low molecular weight metabolites (e.g. AMP, ADP, ATP, acetyl CoA, acetyl phosphate and carbamoyl phosphate).

It has been suggested that small molecules, not macromolecules, dictate the upper temperature limit of life. This view is based on observations (albeit in vitro) that key metabolic intermediates, such as the nicotinamide cofactors, are highly unstable at temperatures as low as $95{ }^{\circ} \mathrm{C}$ [15]. Strain 121 should provide an excellent testbed for analysis of putative mechanisms of cofactor stabilization (such as molecular channeling [16]) or of any propensity to rely on more stable alternative chemical moieties (such as Fe-S proteins instead of nicotinamide cofactors [17]). 


\section{Origins of life}

Kashefi and Lovley [1] do not report where the 16S rRNA sequence is positioned in the universal tree of life [18]. However, its high relatedness to Pyrodictium and Pyro-baculum appears to position it as a relatively deep branch within the Crenarchaeotal lineage. This branching point, together with the apparently 'primitive' form [19] of chemoautotrophic energy transfer (formate- $\mathrm{F}^{111}$ redox pair) in strain 121, is consistent with the currently favored view [20,21] of a high temperature - rather than low temperature - origin oflife (or at least a thermophilic Last Common Ancestor).

\section{To sum up}

The newly isolated hyperthermophilic archaeal strain 121 grows slowly at $121{ }^{\circ} \mathrm{C}$ and even survives short periods at $130{ }^{\circ} \mathrm{C}$. This is another organism that grows best at temperatures well in excess of $100{ }^{\circ} \mathrm{C}$ ! We should not be astonished so much by the numerical increments but by the biochemical implications of this fact, and we should be excited by the scope provided by this and similar organisms to further our understanding of the evolution and adaptation of molecular structures and systems.

And what about the upper limit of life? It appears improbable that the end-point ofthis search is represented by strain 121. The consensus view is that the true upper limit, where the energetic burden imposed by molecular repair and resynthesis becomes unsustainable, will probably lie in the region of $140-150{ }^{\circ} \mathrm{C}$ [22].

\section{References}

1 Kashefi, K. and Lovley, D. (2003) Extending the upper temperature limit for life. Science 301, 934

2 Blochl, E. et al. (1997) Pyrolobus fumarii, gen. and sp. nov., represents a novel group ofarchaea, extending the upper temperature limit oflife to $113^{\circ} \mathrm{C}$. Extremophiles 1, 14-21

3 Brock, T.D. and Freeze, H. (1969) Thermus aquaticus gen. n. and sp. n. a non-sporulating extreme thermophile. J. Bacteriol. 98, $289-297$

4 Fiala, G. and Stetter, K.O. (1986) Pyrococcus furiosus sp. nov. represents a novel genus of marine heterotrophic archaeabacteria growing optimally at $100^{\circ} \mathrm{C}$. Arch. Microbiol. 145, 56-61

5 Takai, K. et al. (2001) Distribution of archaea in a black smoker chimney structure. Appl. Environ. Microbiol. 67, 3618-3629

6 Schrenk, M.O. et al. (2003) Incidence and diversity ofmicroorganisms within the walls of an active deep-sea sulfide chimney. Appl. Environ.Microbiol. 69, 3580-3592

7 Robb, F.T. and Clark, D.S. (1999) Adaptation of proteins from hyperthermophiles to high pressure and high temperature. $J$.

Mol. Microbiol. Biotechnol. 1, 101 -105

8 Daniel, R.M. and Cowan, D.A. (2000) Biomolecular stability and life at high temperatures. Cell. Mol. Life Sci. 57, 250-264

9 Daniel, R.M. et al. (1996) The denaturation and degradation of stable enzymes at high temperatures. Biochem. J. 317, 1 -11

10Jaenicke, R. et al. (1996) Structure and stability of hyperstable proteins. Adv. Protein Chem. 48, 181 -269

11Adams, M.W.W. (1993) Enzymes and proteins from organisms that grownearand above 100 degrees C. Annu. Rev. Microbiol. 47, 627-658

12Britton, K.L. et al. (1999) Structure determination of the glutamate dehydrogenase from the hyperthermophile Thermococcus litoralis and its comparison with that from Pyrococcus furiosus. J. Mol. Biol. 293, 1121-1132

13 Vetriani, C. et al. (1998) Protein thermostability above 100 degrees C:a key role for ionic interactions. Proc. Natl. Acad. Sci. U. S. A. $95,12300-12305$

14White, R.H. (1984) Hydrolytic stability of biomolecules at high temperatures and its implication for life at 250 degrees C. Nature $310,430-432$

15Hudson, R.C. et al. (1993) Glutamate dehydrogenase from the extremely thermophilic archaebacterial isolate AN1. Biochim. Bio-phys. Acta 1202, 244-250

16 Van der Casteele, M. et al. (1990) Pathways ofarginine biosynthesis in extremely thermophilic archaeo- and eu-bacteria. $J$. Gen. Microbiol.136, 1177-1183 
17 Daniel, R.M. and Danson, M.J. (1995) Did primitive microorganisms use non-heme iron proteins in place of NAD/P? J. Mol. Evol. 40, 559-563

18 Pace, N.R. (1997) A molecular view of microbial diversity and the biosphere. Science 276, 734-740

19 Vargas, M. et al. (1998) Microbiological evidence for Fe(III) reduction on early Earth. Nature 395, 65-67

20Wachtershouser, G. (1998) A case for a hyperthermophilic chemolithoautotrophic origin of life in an iron-sulfur world. In

Thermophiles: The Keys to Molecular Evolution and the Origins of Life? (Wiegel, J. and Adams, M.W.W., eds), pp. 47-58,

Taylor and Francis

21Di Giulio, M. (2003) The ancestor of the Bacteria domain was a hyperthermophile. J. Theor. Biol. 224, 277-283

22Stetter, K.O. (1998) Hyperthermophiles: Isolation classification and properties. In Extremophiles: Microbial life in Extreme Environments (Horikoshi, K. and Grant, W.D., eds), pp. 1 -24, Wiley-Liss

23Sharp, R.J. et al. (1991) Heterotrophic thermophilic Bacilli. I n Thermophilic Bacteria (Kristjansson, J., ed.), pp. 19-50, CRC Press

24Brock, T.D. et al. (1972) Sulfolobus: a new genus of sulfur oxidizing bacteria living at low pH and high temperature. Arch. Mikrobiol. 84,54-68

25Zillig, W. et al. (1981) Thermoproteales: a novel type of extremely thermoacidophilic anaerobic archaebacteria isolated from Icelandic solfataras. Zbl. Bakt. Hyg. I. Abt. Orig. C2, 205-227

26 Stetter, K.O. et al. (1983) Pyrodictium gen. nov., a new genus of submarine disc-shaped sulfur reducing archaebacteria growing optimally at $105^{\circ} \mathrm{C}$. Syst. Appl. Microbiol. 4, 535-551

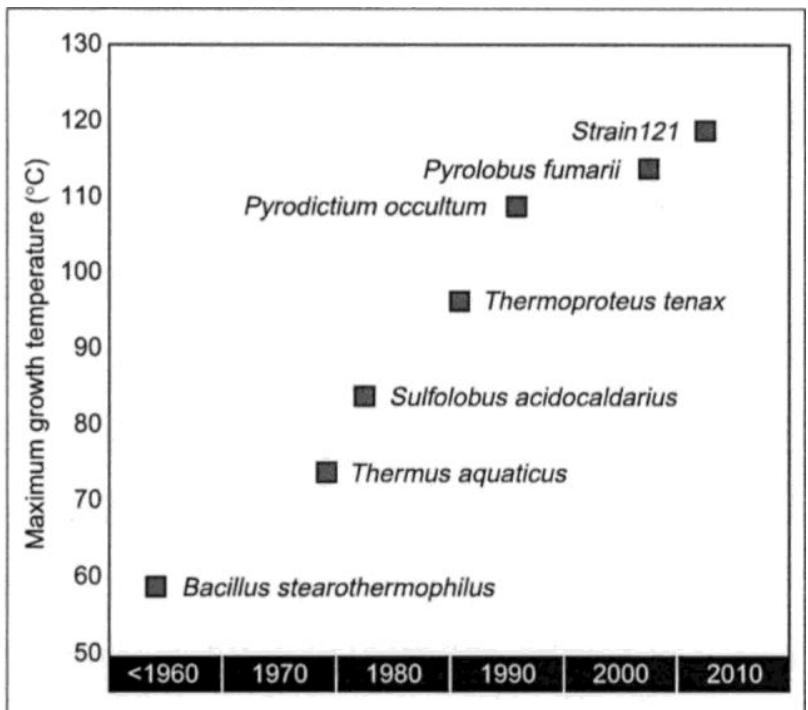

Figure 1. The rise of the upper temperature limit of life. Data points indicate the dates that new organisms were reported that have significantly extended the upper temperature limit of life. Included are Bacillus stearothermophilus [23], Thermus aquaticus [3], Sulfolobus acidocaldarius [24], Thermoproteus tenax [25], Pyrodictium occultum [26], Pyrolobus fumarii [2] and Strain 121 [1]. 